Todd Samuelson and Cait Coker

\title{
How we brought 3,000 people to the library... With the help of Mr. George R. R. Martin
}

$\mathbf{T}$ wenty years ago, George R. R. Martin deposited his archive (consisting of manuscripts, correspondence, and editions of his works) at the Texas A\&M University Libraries. This disposition was the culmination of many years' effort by librarians and members of the Texas science fiction community. Martin had visited Texas A\&M multiple times as a guest of honor at AggieCon, the oldest student-run fantasy and science fiction convention in the country, and on one of his visits

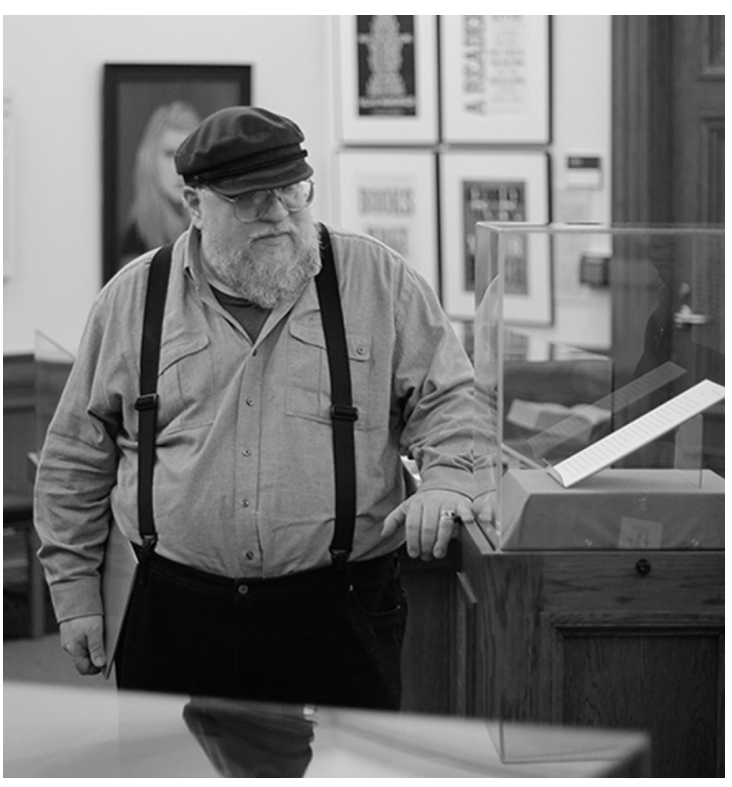
had provided. His interactions with librarians showed him that his work would be valued thetected, and protected, a place among one of the country's largest genre collections of its kind.

From the perspective of the library, the Martin donation represented an attempt to develop a relationship with an award-winning author, who also showed a great deal of future promise. Several Iconic author George R. R. Martin inspects manuscripts, librarians, includeditions, and artifacts from his collection on display in ing Steven Escar the Deeper Than Swords exhibit. (Photograph by Todd Smith, who travSamuelson.)

eled to pick up had received a tour of the university's Special Collections, which was then housed in Sterling C. Evans Library. He had also met and had multiple conversations with the unit's director, Don Dyal.

In opting to place his archive at Texas A\&M (a university with which the author had no immediate connection), Martin based his decision on the assurance of care and quality, which his tour of the library facilities the first deposit of books and manuscripts, had begun to build a collaborative connec-

Todd Samuelson is curator of rare books and manuscripts director, Book History Workshop Cushing Memorial Library and Archives at Texas A\&M University Libraries, e-mail: toddsamuelson@library.tamu.edu, and Cait Coker is coordinator of research services curator, Science Fiction and Fantasy Research Collection, at Cushing Memorial Library and Archives, e-mail: ccoker@library.tamu.edu

C 2013 Todd Samuelson and Cait Coke 
tion with Martin. The relationship matured as the author sent copies of his materials at regular intervals and as the library worked to house, index, and preserve the collection. The archive quickly became available to scholars of Martin's work, the genre, and its growing impact upon popular culture.

\section{The exhibition}

Two years ago, Martin returned to Texas A\&M for the first time since his papers had arrived. The occasion for his visit was the opening of "Deeper Than Swords," an exhibition celebrating his oeuvre, together with a series of events including a book signing and lecture. In the years between the placement of his archive and the exhibition, Martin's reputation and readership had grown. He had transformed from a successful fantasy and science fiction author into an instantly recognizable figure and the source of a cultural phenomenon, thanks to the popularity of his bestselling fantasy series, A Song of Ice and Fire. The Texas A\&M University Libraries had grown, as well. One particular development was the renovation and dedication of Cushing Memorial Library, the oldest free-standing library building on campus, as the home of Special Collections (including the Science Fiction Research Collection and Martin's papers).

As with the earlier negotiations that brought his papers to the university, the process of securing Martin's appearance at Cushing Library drew upon the relationship he had built with Cushing librarians. Having kept in regular contact with Martin over the years, confirming donation arrivals and periodically answering requests for copies and other reference assistance, we approached Martin about creating a large-scale exhibit on his work at which he could preside as a special and honored guest. A date was confirmed for 18 months hence. Our timing proved fortunate, since due to the acceleration of his public appearances, Martin's current calendar is booked through 2017.

In organizing the exhibition, we began conceptualizing events with consideration of the great potential that they could have for the library. In 2010, we had produced with former curator Hal W. Hall an exhibition entitled "One Hundred Years Hence," which drew upon the science fiction and fantasy collection. Its reception and ongoing popularity among students, faculty and staff, and the community suggested the possibilities for a Martin-focused exhibition. We began proposing events that would capitalize upon this enthusiastic audience. The foresight of library administrators-foremost among them J. Lawrence Mitchell, director of Cushing Library-communicated the potential of this project to the University Libraries' marketing team and to the dean, who was supportive of the events and committed wide resources to planning and promoting the exhibition.

\section{Building the exhibit}

We visualized an exhibit that would frame Martin's work both biographically and culturally. After initial conversations with Martin to confirm his preferences in overall design, we began to discuss how best to demonstrate the breadth of his work and the intellectual and artifactual richness of the collection. With the runaway success of his fantasy cycle, some readers have not encountered his beginnings in science fiction, and comparatively few remember his roots in the burgeoning fan culture from the 1960 s to the 1980 s. We identified and procured a few additional items not present in the collection-early Marvel comic books that printed his first letters, a more recent Time Magazine that christened him "the American Tolkien"-and noted influential titles referenced by Martin in his autobiographical essays.

In addition to selecting items from the Martin archive, the curators decided to highlight and interrogate the iconography of Martin's work-much of which has become instantly recognizable. These images have been integrated into the wider cultural consciousness through the publication of the novels and the success of HBO's Game of Thrones series.

One of Martin's preferred artists, John Picacio, is a resident of San Antonio and one of the best-respected genre artists of the day. Through a connection with Charles D. Tolliver and the Fandom Association of Central 
Texas, we contacted Picacio and negotiated rights to use his artwork in the exhibit and its promotional materials. Because of Picacio's generous collaboration with the curators, Cushing Library was able to acquire several original drawings for the exhibition, which have become part of the permanent collections. Simultaneously, we identified two other artists and approached them about collaborating on the project.

Artist Evangeline Owen worked with the curators in developing interpretations of selected figures from the novels to present in portraits highlighting their distinctness as characters; the libraries commissioned four acrylic paintings and three digital images to be included in the exhibit.

Similarly, Anise Press, a Texas-based press known for its cards and posters using literary quotes, set wood and metal types to letterpress print a suite of four broadsides. These finely produced posters,

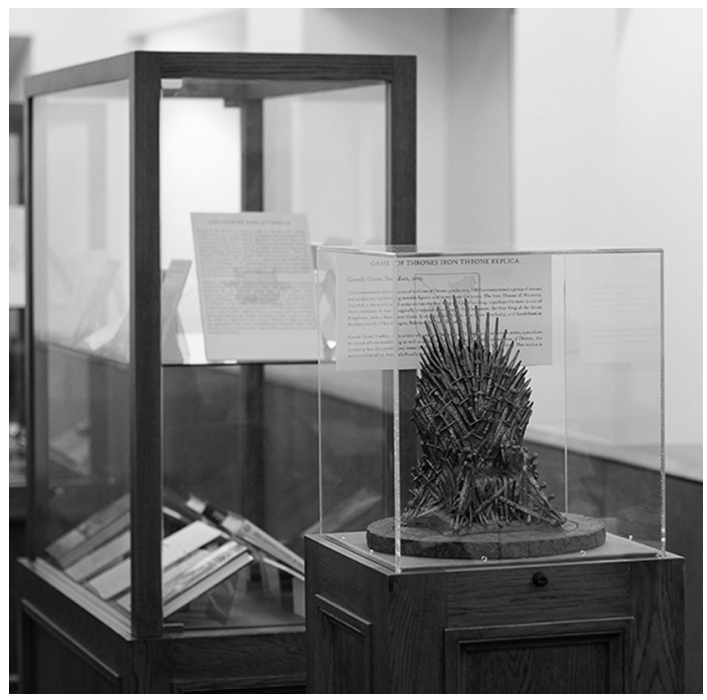

The second gallery of the exhibit contains cases devoted to Martin's influence in his genre, including a large selection of international and translated editions. (Photograph by Todd Samuelson.) document that simultaneously describes the selected objects and presents a narrative about the value, research potential, and cultural significance of the items in the collection. This text, combined with images of many of the objects chosen for inclusion, was produced as an exhibition catalog that documents the project. The University Libraries' Graphics Designer Kim Topp worked closely with us in the presentation of the catalog, which also contains a preface by the Dean of the Libraries David Carlson and introductory essays by Steven Escar Smith and Lisa Tuttle, a close friend of Martin's and well-known author whose papers are also housed in Cushing Library. Each visitor to Cushing Library was given a complimentary copy of the publication at the exhibition opening.

Concurrently, we worked on designing and fabricating the exhibit itself. A central gallery dedicated to A Song of Ice and Fire contains five large vitrines (each which were also incorporated into the exhibition, provided visual designs of statements from Martin's work having to do with reading, writing, and the impact of language. These three collaborations provided widely varying interpretations of Martin's work and a vivid visual presentation for the walls of the gallery.

\section{Preparation and production}

As we worked to identify objects that best articulated the creative development, publication, and impact of Martin's work, we also examined secondary literature-from scholarly monographs to interviews with the author. This research was incorporated into a dedicated to one of the published novels) in a ring around a smaller case, which contains unpublished pages from the forthcoming Winds of Winter. In addition to the pieces of original and commissioned artwork, the gallery contains large informational panels containing our curators' statement, a biography of the author, and essays about Martin's work and its cultural significance. An adjoining gallery contains cases that present the development of Martin's early work. These contain sections on his influences and juvenilia, the landmark works of the first half of his career, and his many collaborations. Alcoves in this gallery contain a representative sample of interna- 
tional editions, as well as framed oversized maps of the lands from his $A$ Song of Ice and Fire sequence. The details of the installation -from the reproduction sword and war hammer hung on the gallery walls to the sigils we designed which appeared as heraldic symbols on labels and panels_-were intended to link the narrative of the exhibition to Martin's iconic writing.

\section{The events}

As the exhibition was being developed, our ambition was to draw in the largest possible

audience to see the work, engage with Martin, and to introduce the participants to Cushing Library. Aware that we would be accessing a demographic which, in many cases, had never entered a special collections, we wanted to demonstrate the values and

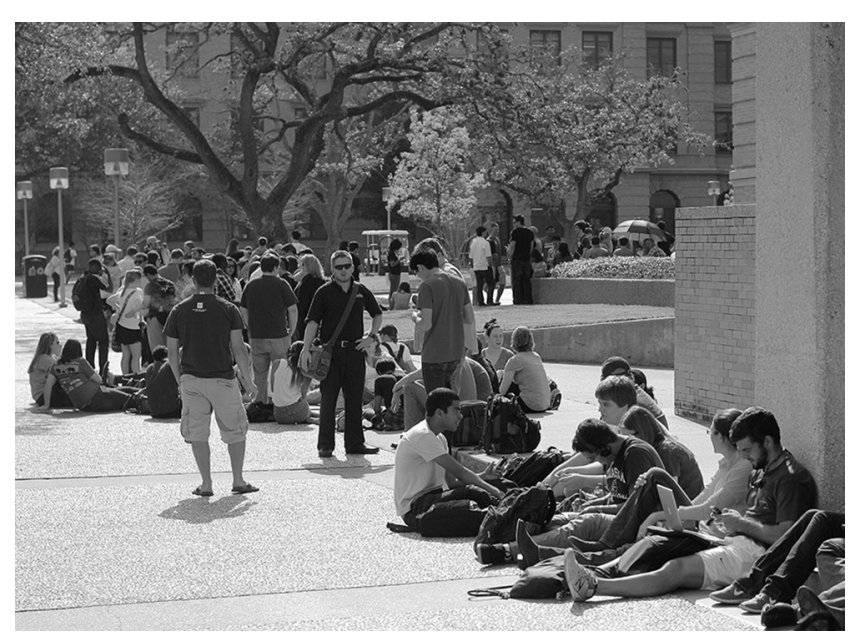

Students outside Cushing Memorial Library at Texas A\&M University wait to meet George R. R. Martin at the library's book signing and exhibition opening. (Photograph by Todd Samuelson.) of "Deeper Than Swords." We also organized a book signing, which was attended by 650 individuals, including 150 "expedited line" tickets that confirmed the opportunity to meet the author and obtain his signature. Together, these two events raised more than $\$ 33,000$ for the libraries, with proceeds going towards the support of the libraries' exhibition programs.

Anticipating the size of Martin's audience, we booked a campus venue that seats 2,400 for Martin's talk about his life as a reader and for his moderated interview. After observing public anticipation for the event, HBO sponsored resources of the library. In order to increase the opportunities for the audience to engage with the exhibition, we planned a series of events to draw in Martin's readers and fans: a fundraising dinner and exhibition preview with the author, a book signing to increase traffic for the opening, and a lecture and Q\&A available to the public at large. Working closely with the University Libraries marketing team, we succeeded in realizing these concepts:

For the fundraising dinner, we commissioned local chef Tai Lee (who had appeared on the Food Network) to develop a series of themed dishes. Lee's Mobile Bistro food truck was also commissioned to sell street-food variations of these recipes-including lemon cakes_on campus during the public opening an advance screening of the first episode of season three of Game of Thrones, as well as a catered reception for donors and library employees. Martin, who had spent the previous week on $\mathrm{HBO}$ 's press junket, noted that the A\&M audience was the largest and most enthusiastic he had seen. The talk and interview, which were recorded, have received tens of thousands of additional viewings from YouTube and Martin's Web site. ${ }^{1}$

Finally, we arranged a private tour of the exhibition for Martin, allowing him the opportunity to focus on the presentation of his collection, as well as to see his holdings in situ in the stacks. Since his initial deposit the collection has grown to encompass more than 200 hundred boxes of processed manuscripts and memorabilia, and nearly 1,000 volumes of first editions and translated works. His response in seeing his work, both presented for the public and preserved in archival boxes, was uniformly positive. The 3,000 visitors who

(continues on page 356) 
"How to zombie-proof your home." Working one-on-one with students who struggled, and reiterating concepts like keywords, synonyms, and scholarly versus popular articles, helped these students understand how the zombie themed topics could be applied to research on real-life situations.

Despite these drawbacks, overall we found the quality of work greatly improved over previous quarters in which there was no class theme and students researched any topic of their choosing. Along with this, students were more enthusiastic about coming to class. Both authors solicited anonymous feedback throughout the quarter. When asked specific questions about the use of the zombie topic, the answers reported were positive. One student wrote, "My instructor used everyday topics to relate to the material we were covering in class. She used zombies as a way to make the class interesting. I actually looked forward to coming to class and doing the work! I mean, how many colleges offer courses on zombies!"

Another student commented, "The structure of this course is very refreshing. The information is relayed in such a fun manner that I don't even realize I am learning. Which is awesome." For the most part, students really enjoyed all the in-class activities and liked having zombies in class with them. Despite the generational differences in the student population, the consensus in both sections of the course was that the zombie theme made research fun and not what students thought information literacy class would be: boring.

With the help a zombie apocalypse, our students were able to learn some valuable searching skills while researching topics that were serious and meaningful. Our students, through hands-on in-class activities and required research assignments were able to fulfill the information literacy requirements set forth by Harrison College. As instructors and librarians this made us proud. We hope, like the fictitious legends of the undead, that our students go on walking toward the real flesh, that of lifelong learning.

\section{Notes}

1. For example, see Barbara P. Heuer, "Using Popular Media to Build Literacy," New Directions for Adult and Continuing Education, no. 115 (2007): 55-62; Amy Springer and Kathryn Yelinek, "Teaching with The Situation: Jersey Shore as a Popular Culture example in Information Literacy Classes," CERL News 72 (2011): 78-118.

2. Harrison College 2012-13 Catalog, http://bit.ly/YWXgFD.

3. Matt Upson and C. Michael Hall, "Library of the Living Dead," http://blogs.mcpherson. edu/library/zombie-guide-to-the-library/.

4. Margeaux Johsnon, Amy Buhler, and Chris Hillman, "The Library is Undead: Information Seeking during the Zombie Apocalypse," Journal of Library Innovation 1(2010):29-43. The corresponding zombie survival LibGuide is available at http://guides. uflib.ufl.edu/zombie

5. View zombie themed materials used in the course at https://sites.google.com/site /lafayetteinf/ and http://inf1100.wikispaces. com. $n$

("How we brought...cont. from page 345) participated in the events shared his enthusiasm with unrestrained fervor.

The success of this venture was due largely to the presence of an author and cultural figure of the stature of George R. R. Martin. It is also a testament to the collaborations possible when an institution brings together author-donors, local artists and businesses, and the community. This exhibition created a narrative of the power of words, demonstrating how Martin's often-cited influences as a young and avid reader led to his own creation of works that are now shaping literature and popular culture. We believe that our efforts to present that process of influence and impact extends to the library as well, and to the readers who entered to see the exhibition.

\section{Note}

1. http://deeperthanswords.library.tamu. edu/events.html $\boldsymbol{n}$ 